\title{
NOTE ON ORTHOGRAPHY AND DATES
}

Aside from card-carrying epigraphers, most readers of specialized or even general publications about the Maya have experienced the confusion and frustration of trying to remain current with the rapidly changing readings, interpretations, and orthography of Classic glyphs, kings' names, and so forth (see Montgomery 2001:I3). My decisions on how to handle these matters are outlined below.

In general, I try to employ the orthography for Maya words that has been accepted by the Academía de Lenguas Mayas in Guatemala, because the research on which it was based and the primary site discussed (Tikal) are in Guatemala. However, Guatemalan archaeologists also have eliminated, in national publications, Spanish diacritical marks on the names of sites, cultural phases, and ceramic units drawn from indigenous languages. I have chosen to retain these markings and spellings and use the spellings of site names as they customarily appear (or have appeared) on maps produced in the United States by the National Geographic Society.

The above principles do not provide a solid basis for selecting Yukatekan versus Ch'olan Mayan orthography. The western and southern parts of the southern lowlands seem to have spoken and written Ch'olan during the Late Classic period, while the northern lowlands used Yukatekan (although this too is a matter of argument). The central area, from just south of the Petén lakes chain northward to perhaps the Río Bec zone, might have been bilingual in Yukatekan and Ch'olan. Indeed, the whole lowlands might have been bilingual. But given the likelihood that (I) Classic Maya inscriptions might have been written using a combination of Yukatekan and Ch'olan and (2) the south-central and particularly the Tikal zones were not primarily Ch'olan-speaking, I have opted to use Yukatekan spellings. In general, those of us working in the Petén lakes area accept continuities in Yukatekan and Itzaj Maya dialects for the region. 
What all this means is that, for example, I spell certain words with the Yukatekan $k$ rather than the Ch'olan ch (e.g., kan rather than chan). In addition, I have chosen to use $j$ for both the hard and soft $h$ sound. I do not incorporate hypothesized long vowels except as such spellings occur in direct quotations.

Finally, in Yukatekan Mayan plurals are expressed with an $o b$ ending, for example k'atunob to mean multiple k'atuns. Purists will shudder, but, for greater ease of reading, I use the English convention of $s$ to denote plurals.

Numerous words in the Maya languages are used in the text. In general, they are italicized when first used and in roman type thereafter. Important exceptions are may (pronounced "my"), the Maya 256-year cycle, which is always italicized to avoid confusion with the English auxiliary verb may; and way (pronounced "wye"), meaning spirit companion, which is always italicized to avoid confusion with the English word.

Finally, as much as possible, Maya dates reported here have been correlated to the Gregorian calendar using the Goodman-MartínezThompson correlation and the 584,283 correlation constant. 